\title{
Effects of Oral Copper Administration to Pregnant Heterozygous Brindled Mice on Fetal Viability and Copper Levels
}

\author{
Tooru Kasama and Harumi TANAKA ${ }^{1, *}$ \\ Division of Mental Retardation and Birth Defect Research, \\ National Institute of Neuroscience, \\ National Center of Neurology and Psychiatry, \\ Ogawahigashi, Kodaira, Tokyo 187, Japan
}

(Received July 24, 1989)

Summary Copper (6 ppm) was administered to pregnant heterozygous brindled and normal mice from 13 to 18 days gestation. The copper and zinc concentrations in the cerebrum, cerebellum, liver, and kidneys of mothers and their fetuses were determined. The placental concentrations in fetuses of heterozygous mothers administered copper were also determined. The heterozygous mothers had smaller numbers of live fetuses than the normal mothers, but had the same number as normal mothers when copper was administered. The hepatic copper concentration in the heterozygous mothers was lower than that in the normal mothers and was not increased by the administration. The body and tissue wet weights of all fetuses were unaffected by the maternal genotype or drinking fluid. The cerebral copper concentrations in hemizygous and heterozygous fetuses were increased by the copper administration but did not reach normal levels. The hepatic and renal concentrations remained unchanged. The cerebral copper concentrations in normal fetuses of both heterozygous and normal mothers were increased by the copper administration. The copper administration increased the copper concentrations in liver of normal fetuses of heterozygous mothers and in kidneys of normal fetuses of normal mothers. The placental copper concentration in hemizygous fetuses was higher than those in heterozygous and normal fetuses. These results suggested that oral copper administration to pregnant females could improve an abnormal copper distribution in hemizygous and heterozygous fetuses without affecting fetal growth.

Key Words brindled mouse, copper administration, copper concentration, fetal mouse, fetal therapy, pregnant mouse

\footnotetext{
1 笠間 透, 田中晴美

* To whom correspondence should be addressed.
} 
Menkes' kinky hair disease was first reported by Menkes et al. (1), and Hunt found that brindled mutant mice have almost the same characteristics as patients with Menkes' disease(2). Although an abnormal copper distribution has been demonstrated in both human patients and brindled mice, their responses to copper therapy are different (3). A little improvement of clinical symptoms was reported in a summary of previous therapeutic trials in humans (4), whereas brindled mice, that die at approximately 2 weeks of age without treatment, survived with copper supplementation after birth (5-8). This discrepancy in the response to copper therapy between human patients and brindled mice has not been clearly explained. The difference in the development stage is one possible explanation. The estimated hepatic copper concentration suggested that mice were born at an earlier stage of development than humans (9). It was also indicated that brain damage might have already occurred before birth (10). The possibility of the prenatal diagnosis of Menkes' disease was reported (11) and it was proposed that therapy should be started as soon as possible (4). It has become important to explore the possibility of fetal therapy.

Oral copper administration to pregnant females is considered to be one possible way of copper supplementation for affected fetuses. Our previous report, showing that the oral administration of copper to pregnant normal mice increased the cerebral copper concentration in neonates without disturbing growth in utero (12), supported this possibility. On the other hand, the malabsorption of copper in adult heterozygous brindled females (13) and the defective placental transfer of copper to hemizygous fetuses (14) were reported.

There have been, however, few reports of the administration of copper to fetuses of brindled mice. Although Mann et al. reported copper administration to pregnant brindled mice, they studied the transfer of ${ }^{64} \mathrm{Cu}$ with one intraperitoneal injection (14). So there was little information on the effect of copper administration to pregnant females.

The purposes of this study are to determine the difference in the placental transfer of copper between heterozygous and normal mothers, and to clarify the possibility of fetal therapy, including the prevention of brain damage, in hemizygous fetuses. Therefore, we investigated the effects of copper administration to pregnant heterozygous mice on their fetuses. We report here that copper administration improved the copper deficiency in the cerebrum of affected fetuses. The difference in the response to the administration as to the fetal genotypes, and that of normal fetuses between heterozygous and normal mothers are also reported.

\section{MATERIALS AND METHODS}

Animals. The $\mathrm{C} 3 \mathrm{H} / \mathrm{HeJ}-\mathrm{Mo}^{\text {br }}$ mice used were 12 heterozygous and 7 normal female mice, and 9 normal male mice, which were offspring obtained in our laboratory through mating of heterozygous female and normal male mice. The original breeding pairs were purchased from Jackson Laboratory (Maine, U.S.A.). 
The mice were fed a standard diet (MM-3; Sankyo Lab., Tokyo, Japan) and given tap water, except for the period of copper administration, without any restriction. The MM-3 contained $1 \mathrm{mg}$ of copper per $100 \mathrm{~g}$ dry weight and the tap water only a trace amount.

Experiment. Heterozygous and normal female mice of 9-39 weeks old, with body weights of 18-27 g, were mated with normal male mice to produce pregnancies. The day when a plug and/or sperm in a vaginal smear were/was detected was taken as 0 day gestation. The pregnant mice drank a cupric sulfate solution containing 6 ppm of copper $(\mathrm{Cu})$ or tap water (TW) from 13 days gestation to 18 days gestation. The copper concentration was decided on the basis of preliminary experiments using normal mice in our previous report (12): a concentration higher than $6 \mathrm{ppm}$ decreased the amount drunk by adult male mice and gave no live neonatal mouse when it was administered to the mother from 13 days gestation to delivery. $\mathrm{Cu}$ was administered to 6 heterozygous and 3 normal mothers, and TW to 6 heterozygous and 4 normal mothers.

Tissue preparation. At 18 days gestation, fetuses were obtained by means of cesarean section under anesthesia with chloroform. The cerebrum, cerebellum, liver, and kidneys of each fetus were removed immediately after the cesarean section. The placenta of each fetus from 2 heterozygous mothers with $\mathrm{Cu}$ was also separated. The cerebrum, cerebellum, liver, and kidneys of the mothers were also prepared. The sex of each fetus was determined, according to whether or not a uterus was detected by stereoscopic microscopy. The hepatic copper concentration allowed discrimination of hemizygous (br/y) from normal male fetuses, and of heterozygous $(\mathrm{br} /+)$ from normal female fetuses $(6,14)$. Normal male and female fetuses were combined as normal fetuses because there was no difference in the values observed. Since the cerebellum showed the same trend as the cerebrum, all cerebellar data are not presented. All tissues thus prepared were weighed, washed with distilled water, and then stored frozen until the measurement of copper and zinc concentrations.

Metal measurement. The copper and zinc concentrations in tissues were measured after lyophilization and wet-ashing in $\mathrm{HNO}_{3}-\mathrm{HClO}_{4}$ according to our previous report (12).

Statistical analyses. Data out of the mean \pm 3 SD range were omitted for statistical analyses and from the results. Data were statistically examined by means of analysis of variance (ANOVA), with Scheffe's multiple comparison (ANOVA-MC) if necessary. A $p$-value of less than 0.05 was considered to be statistically significant. The data were first examined by means of two-way ANOVA as to the maternal or fetal genotype, and the maternal drinking fluid. When a difference(s) was (were) detected, the effect of the maternal or fetal genotype for each of the maternal drinking fluids was examined independently. The effect of the maternal drinking fluid for each of the maternal or fetal genotype was also examined independently. 


\section{RESULTS}

Body weights of mothers and litter sizes

The total litter sizes in Table 1 represent the sums of live fetus(es) and that (those) resorbed. All four groups had the same total litter size. The number of live fetuses was proportional to the gain in body weight during pregnancy in all mothers $(r=0.8893)$. The heterozygous mothers with TW had significantly smaller numbers of live fetuses and showed lower gains in body weight than the heterozygous mothers with $\mathrm{Cu}$ and the normal mothers with TW. When the mothers drank $\mathrm{Cu}$, the maternal genotype made no difference. The copper administration reduced the difficulty of the heterozygous mothers in maintaining their pregnancies.

\section{Metal concentrations in maternal tissues}

Cerebral wet weights and copper concentrations showed no significant differences among the four groups (Table 2). Only in the cerebrum was a lower zinc concentration in the heterozygous than the normal mothers with TW detected.

A different response to copper administration as to the maternal genotype was observed in the hepatic wet weight and copper concentration. The difference in hepatic wet weight was due to the difference between the heterozygous mothers with $\mathrm{Cu}$ and those with TW. The liver of the heterozygous mothers had a lower copper concentration than that of the normal mothers. Although the hepatic copper concentration in the normal mothers remarkably increased with the administration,

Table 1. Body weight gains during pregnancy (Gain) and litter sizes of heterozygous and normal pregnant mice administered copper $(\mathrm{Cu})$ or tap water $(\mathrm{TW}){ }^{1}$

\begin{tabular}{|c|c|c|c|c|}
\hline \multirow{2}{*}{$\begin{array}{l}\text { Genotype } \\
\text { Drink }\end{array}$} & \multicolumn{2}{|c|}{ Heterozygous } & \multicolumn{2}{|c|}{ Normal } \\
\hline & $\mathrm{Cu}$ & TW & $\mathrm{Cu}$ & TW \\
\hline Number & 6 & $5^{2}$ & 3 & 4 \\
\hline $\operatorname{Gain}^{3}(\mathrm{~g})$ & $12.8 \pm 1.5^{*}$ & $7.3 \pm 1.8^{\mathrm{a}}$ & $13.7 \pm 2.7$ & $14.1 \pm 2.6$ \\
\hline \multicolumn{5}{|l|}{ Litter size } \\
\hline Total $^{4}$ & $6.7 \pm 0.7$ & $5.2 \pm 0.7$ & $6.3 \pm 0.5$ & $6.3 \pm 0.8$ \\
\hline Live $^{3}$ & $5.2 \pm 1.1^{*}$ & $2.4 \pm 0.5^{\mathrm{a}}$ & $5.7 \pm 1.3$ & $5.8 \pm 1.3$ \\
\hline \multicolumn{5}{|l|}{ Genotype } \\
\hline $\mathrm{br} / \mathrm{y}$ & $1.8 \pm 1.1$ & $1.6 \pm 1.0$ & & \\
\hline $\mathrm{br} /+$ & $0.7 \pm 0.5$ & $0.2 \pm 0.4$ & & \\
\hline Normal & $2.7 \pm 1.5$ & $0.6 \pm 0.5$ & $5.7 \pm 1.3$ & $5.8 \pm 1.3$ \\
\hline
\end{tabular}

\footnotetext{
${ }^{1}$ Values are means \pm SD for the numbers given. ${ }^{2}$ One mouse was rejected, as explained in the text. ${ }^{3}$ The interaction between the maternal genotype and drink was detected with $2 \times 2$ ANOVA. ${ }^{4}$ No interaction between the maternal genotype and drink was detected. The results of one-way ANOVA are expressed as superscripts, as follows: * significant difference between $\mathrm{Cu}$ and $\mathrm{TW}$ for the same genotype; ${ }^{\mathrm{a}}$ significant difference between the heterozygous and normal mothers for the same drink.
} 
Table 2. Tissue wet weights and metal concentrations ( $\mu \mathrm{g} / \mathrm{g}$ wet weight) of heterozygous and normal pregnant mice administered copper $(\mathrm{Cu})$ or tap water $(\mathrm{TW}){ }^{1}$

\begin{tabular}{|c|c|c|c|c|}
\hline \multirow{2}{*}{$\begin{array}{l}\text { Genotype } \\
\text { Drink }\end{array}$} & \multicolumn{2}{|c|}{ Heterozygous } & \multicolumn{2}{|c|}{ Normal } \\
\hline & $\mathrm{Cu}$ & TW & $\mathrm{Cu}$ & TW \\
\hline Number & 6 & 6 & 3 & 4 \\
\hline \multicolumn{5}{|l|}{ Cerebrum } \\
\hline Wet $\mathrm{wt}^{2}(\mathrm{mg})$ & $312 \pm 2$ & $314 \pm 2$ & $312 \pm 2$ & $315 \pm 3$ \\
\hline Copper ${ }^{2}$ & $4.1 \pm 1.0$ & $4.6 \pm 0.5$ & $5.7 \pm 0.7$ & $4.8 \pm 0.5$ \\
\hline Zinc $^{2}$ & $17.5 \pm 0.7$ & $16.8 \pm 1.0^{\mathrm{a}}$ & $18.4 \pm 1.5$ & $20.4 \pm 2.7$ \\
\hline \multicolumn{5}{|l|}{ Liver } \\
\hline Wet $\mathrm{wt}^{3}(\mathrm{~g})$ & $1.93 \pm 0.18^{*}$ & $1.65 \pm 0.12$ & $1.75 \pm 0.16$ & $1.81 \pm 0.10$ \\
\hline Copper ${ }^{3}$ & $5.1 \pm 0.8^{\mathrm{a}}$ & $5.6 \pm 1.5^{\mathrm{a}}$ & $20.3 \pm 4.4^{*}$ & $8.6 \pm 1.0$ \\
\hline Zinc $^{2}$ & $32.7 \pm 3.2$ & $34.8 \pm 3.1$ & $41.3 \pm 7.8$ & $36.0 \pm 2.9$ \\
\hline \multicolumn{5}{|l|}{ Kidney } \\
\hline Wet $\mathrm{wt}^{2}(\mathrm{mg})$ & $447 \pm 49^{\mathrm{a}}$ & $379 \pm 62$ & $347 \pm 7$ & $361 \pm 26$ \\
\hline Copper ${ }^{2}$ & $21.3 \pm 11.4^{\mathrm{a}}$ & $28.4 \pm 9.8^{\mathrm{a}}$ & $5.1 \pm 0.1$ & $5.5 \pm 0.4$ \\
\hline Zinc $^{2}$ & $17.2 \pm 1.4$ & $19.2 \pm 1.5$ & $15.2 \pm 1.2$ & $17.9 \pm 1.5$ \\
\hline
\end{tabular}

${ }^{1}$ Values are means $\pm S D$ for the numbers given. ${ }^{2}$ No interaction between the maternal genotype and drink with $2 \times 2$ ANOVA was detected. ${ }^{3}$ The interaction between the maternal genotype and drink was detected. The results of one-way ANOVA are expressed as superscripts, as follows: * significant difference between $\mathrm{Cu}$ and TW for the same genotype; ${ }^{a}$ significant difference between the heterozygous and normal mothers for the same drink.

no increase was observed in the heterozygous mothers. The hepatic zinc concentration showed no significant differences among the four groups.

In the kidneys, the heterozygous mothers showed a higher copper concentration than the normal mothers, but their zinc concentration was the same as that of the normal mothers. On comparison of the effects of the maternal drinking fluid in the same maternal genotype, the copper administration was found to have no effect on the renal metal concentrations in either heterozygous or normal mothers.

\section{Comparison of the fetal genotype and maternal drinking fluid in fetuses of heterozygous mothers}

No significant interaction was detected between the fetal genotype and maternal drinking fluid in fetuses of heterozygous mothers (Table 3). A difference in fetal body weight was only detected between br/y and normal fetuses of the mothers with $\mathrm{Cu}$. Fetal tissue wet weights were the same in all groups. Administration to the heterozygous mothers was considered not to affect fetal growth.

The cerebral copper concentrations of br/y and br/ + fetuses were the same and significantly lower than that of normal fetuses, regardless of the maternal drinking fluid. The copper administration increased the cerebral copper 
Table 3. Body and tissue wet weights, and metal concentrations ( $\mu \mathrm{g} / \mathrm{g}$ wet weight) of hemizygous $(\mathrm{br} / \mathrm{y})$, heterozygous $(\mathrm{br} /+)$, and normal fetuses from heterozygous or normal mothers administered copper $(\mathrm{Cu})$ or tap water $(\mathrm{TW})$ at 18 days gestation. ${ }^{1}$

\begin{tabular}{|c|c|c|c|c|c|}
\hline \multirow{2}{*}{\multicolumn{2}{|c|}{$\begin{array}{l}\text { Maternal genotype } \\
\text { Fetal genotype }\end{array}$}} & \multicolumn{3}{|c|}{ Heterozygous } & \multirow{2}{*}{$\begin{array}{l}\text { Normal } \\
\text { Normal }\end{array}$} \\
\hline & & $\mathrm{br} / \mathrm{y}$ & $\mathrm{br} /+$ & Normal & \\
\hline \multirow[t]{2}{*}{ Number } & $\mathrm{Cu}$ & 11 & 4 & $15^{2}$ & 17 \\
\hline & TW & 9 & 3 & 7 & 22 \\
\hline \multirow{2}{*}{ Body $\mathrm{wt}^{3,4}(\mathrm{~g})$} & $\mathrm{Cu}$ & $1.12 \pm 0.10^{\mathrm{a}}$ & $1.05 \pm 0.04$ & $1.01 \pm 0.10$ & $1.03 \pm 0.11$ \\
\hline & TW & $1.06 \pm 0.07$ & $0.90 \pm 0.04$ & $0.94 \pm 0.09^{\mathrm{c}}$ & $1.07 \pm 0.08$ \\
\hline \multicolumn{6}{|c|}{ Cerebrum } \\
\hline \multirow[t]{2}{*}{ Wet $\mathrm{wt}^{3,5}(\mathrm{mg})$} & $\mathrm{Cu}$ & $47.2 \pm 4.8$ & $44.7 \pm 2.1$ & $43.1 \pm 5.0$ & $42.4 \pm 3.1$ \\
\hline & TW & $43.9 \pm 2.4$ & $40.8 \pm 2.8$ & $42.7 \pm 2.2$ & $44.6 \pm 3.6$ \\
\hline \multirow[t]{2}{*}{ Copper ${ }^{3,5}$} & $\mathrm{Cu}$ & $0.46 \pm 0.06^{\mathrm{a} *}$ & $0.48 \pm 0.04^{\mathrm{a} *}$ & $0.89 \pm 0.11^{\mathrm{c} *}$ & $0.77 \pm 0.11^{*}$ \\
\hline & TW & $0.32 \pm 0.06^{\mathrm{a}}$ & $0.38 \pm 0.05^{\mathrm{a}}$ & $0.65 \pm 0.09$ & $0.66 \pm 0.07$ \\
\hline \multirow[t]{2}{*}{$\operatorname{Zinc}^{3,5}$} & $\mathrm{Cu}$ & $11.5 \pm 0.6$ & $11.5 \pm 0.4$ & $11.3 \pm 0.7^{\mathrm{c}}$ & $12.9 \pm 1.3^{*}$ \\
\hline & TW & $11.5 \pm 0.8$ & $12.4 \pm 0.5$ & $10.8 \pm 1.1^{\mathrm{c}}$ & $11.9 \pm 1.1$ \\
\hline \multicolumn{6}{|l|}{ Liver } \\
\hline \multirow[t]{2}{*}{ Wet $\mathrm{wt}^{3,5}(\mathrm{mg})$} & $\mathrm{Cu}$ & $69.0 \pm 14.3$ & $69.2 \pm 10.7$ & $64.6 \pm 12.5$ & $69.5 \pm 9.1$ \\
\hline & TW & $66.3 \pm 15.0$ & $55.0 \pm 3.3$ & $60.9 \pm 11.2^{\mathrm{c}}$ & $69.9 \pm 7.6$ \\
\hline \multirow[t]{2}{*}{ Copper 3,5} & $\mathrm{Cu}$ & $3.03 \pm 0.93^{\mathrm{a}}$ & $3.36 \pm 1.27^{\mathrm{a}}$ & $20.0 \pm 3.2^{*}$ & $19.5 \pm 5.5$ \\
\hline & TW & $2.71 \pm 0.4^{\mathrm{a}}$ & $2.01 \pm 0.66^{\mathrm{a}}$ & $15.5 \pm 4.1$ & $17.8 \pm 4.6$ \\
\hline \multirow[t]{2}{*}{$\operatorname{Zinc}^{3,4}$} & $\mathrm{Cu}$ & $29.4 \pm 4.4^{\mathrm{a} *}$ & $31.9 \pm 4.8$ & $37.8 \pm 3.3^{\mathrm{c} *}$ & $44.3 \pm 5.5$ \\
\hline & TW & $37.7 \pm 6.5$ & $39.1 \pm 9.0$ & $41.2 \pm 5.1$ & $42.0 \pm 4.6$ \\
\hline \multicolumn{6}{|l|}{ Kidney } \\
\hline \multirow[t]{2}{*}{ Wet $\mathrm{wt}^{3,5}(\mathrm{mg})$} & $\mathrm{Cu}$ & $9.5 \pm 1.4$ & $9.8 \pm 1.8$ & $10.0 \pm 2.3$ & $9.2 \pm 2.0$ \\
\hline & TW & $10.1 \pm 1.4$ & $8.2 \pm 0.9$ & $9.5 \pm 1.7$ & $9.8 \pm 1.7$ \\
\hline \multirow[t]{2}{*}{ Copper ${ }^{3,5}$} & $\mathrm{Cu}$ & $1.84 \pm 0.37^{\mathrm{ab}}$ & $0.95 \pm 0.29$ & $0.88 \pm 0.21^{\mathrm{c}}$ & $1.12 \pm 0.26^{*}$ \\
\hline & TW & $1.53 \pm 0.22^{\mathrm{ab}}$ & $1.02 \pm 0.05$ & $0.84 \pm 0.12$ & $0.95 \pm 0.17$ \\
\hline \multirow[t]{2}{*}{$\operatorname{Zinc}^{3,5}$} & $\mathrm{Cu}$ & $14.1 \pm 3.3$ & $14.0 \pm 1.7$ & $14.4 \pm 2.9$ & $17.3 \pm 4.7$ \\
\hline & TW & $18.0 \pm 5.0$ & $13.8 \pm 0.6$ & $12.8 \pm 2.3^{\mathrm{c}}$ & $19.8 \pm 4.0$ \\
\hline
\end{tabular}

${ }^{1}$ Values are means \pm SD for the numbers given. ${ }^{2}$ One fetus was rejected, as explained in the text. ${ }^{3}$ No interaction between the fetal genotype and maternal drink in the heterozygous mothers was detected with $2 \times 3$ ANOVA. ${ }^{4}$ The interaction between the maternal genotype and drink in normal fetuses was detected with $2 \times 2$ ANOVA. ${ }^{5}$ No interaction between the maternal genotype and drink in normal fetuses was detected. The results of one-way ANOVA-MC or ANOVA are represented as superscripts, as follows: *significant difference between $\mathrm{Cu}$ and $\mathrm{TW}$ for the same fetal genotype; ${ }^{a}$ significant difference from normal fetuses of the heterozygous mothers for the same drink; ${ }^{b}$ significant difference from br/ + of the heterozygous mothers for the same drink; ${ }^{\mathrm{c}}$ significant difference from normal fetuses of the normal mothers for the same drink.

concentrations of $\mathrm{br} / \mathrm{y}, \mathrm{br} /+$, and normal fetuses. Despite these increases, the cerebral copper concentrations of br/y and br/ + fetuses did not reach normal levels. The cerebral zinc concentration was independent of the fetal genotype or maternal 
drinking fluid.

The hepatic copper concentrations of $\mathrm{br} / \mathrm{y}$ and $\mathrm{br} /+$ fetuses were the same and significantly lower than that of normal fetuses, regardless of the maternal drinking fluid. An increase in the hepatic copper concentration with the copper administration was observed only in normal fetuses. A difference in the hepatic zinc concentration was demonstrated between $\mathrm{br} / \mathrm{y}$ and normal fetuses of the mothers with $\mathrm{Cu}$. The administration decreased the hepatic zinc concentration of $\mathrm{br} / \mathrm{y}$ and normal fetuses.

In the kidneys, the copper concentration of br/y fetuses was significantly higher than those of $\mathrm{br} /+$ and normal fetuses. The copper administration had no effect on the fetal copper and zinc concentrations. The zinc concentration was unchanged by either the fetal genotype or the materal drinking fluid.

\section{Comparison of the maternal genotype and drinking fluid in normal fetuses}

A significant interaction was detected in body weight and hepatic zinc concentration (Table 3). Copper administration to the normal mothers did not cause a change in fetal body weight. The body weight of normal fetuses of the heterozygous mothers was significantly lower and was increased to normal level by the administration.

The cerebral wet weight showed no significant differences among the four groups. Copper administration increased the cerebral copper concentration, regardless of the maternal genotype. The cerebral zinc concentrations of normal fetuses of the heterozygous mothers were lower than those of normal mothers with both $\mathrm{Cu}$ and TW. An increase in zinc concentration was observed in normal fetuses of the normal mothers, but not in those of the heterozygous mothers.

The hepatic wet weight changed in the same way as body weight. Although the administration caused no change in the liver of normal fetuses of the normal mothers, normal fetuses of the heterozygous mothers showed an increase in copper concentration and a decrease in zinc concentration.

The renal wet weight showed no significant differences among the four groups. Although the renal copper concentration in normal fetuses of the normal mothers was increased by the copper administration, that in the case of the heterozygous mothers was unchanged. A difference in renal zinc concentration was detected only between normal fetuses of the heterozygous and normal mothers with TW.

\section{Relationship of copper concentrations in tissues}

The copper concentrations in cerebrum and kidney of fetuses of the heterozygous mothers could be used to distinguish br/y and br/ + fetuses from normal fetuses (Fig. 1). The relationship of the hepatic and renal copper concentrations was so similar to that of the cerebral and renal ones that the relationship was also useful for deciding the fetal genotype (data not shown).

\section{Placental copper concentration}

The copper concentration in placenta of fetuses of the heterozygous mothers 


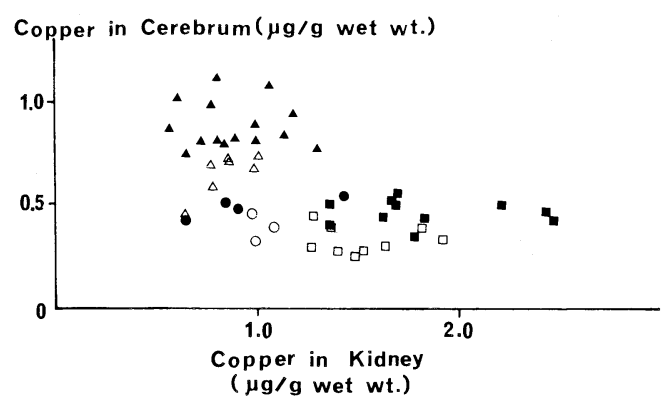

Fig. 1. Relationship between the copper concentrations ( $\mu \mathrm{g} / \mathrm{g}$ wet weight) in the cerebrum (Y-axis) and kidney (X-axis) of fetuses of the heterozygous mothers administered copper $(\mathrm{Cu})$ or tap water $(\mathrm{TW})$. $\mathbf{\square}$, hemizygous fetuses of mothers with $\mathrm{Cu} ; \square$, hemizygous with TW; $\bullet$, heterozygous with $\mathrm{Cu}$; $\bigcirc$, heterozygous with TW; $\mathbf{\Delta}$, normal with $\mathrm{Cu} ; \triangle$, normal with TW.
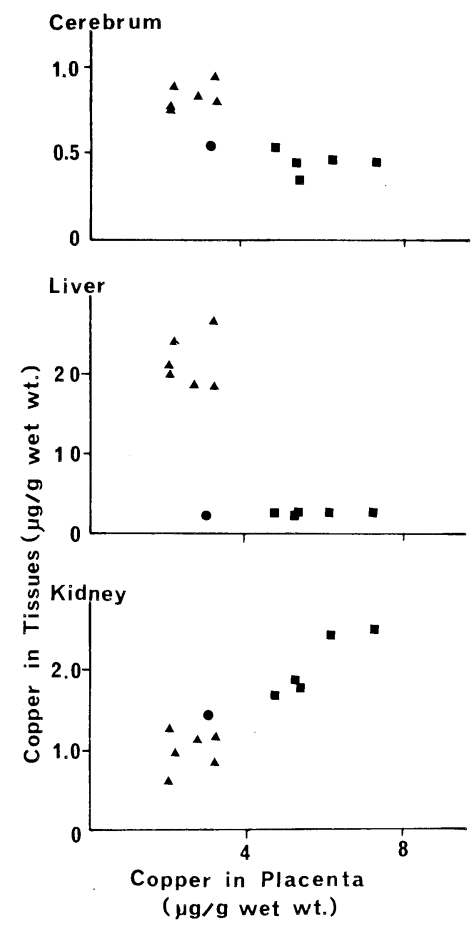

Fig. 2. Relationships between the copper concentrations $(\mu \mathrm{g} / \mathrm{g}$ wet weight) in the placenta (X-axis) and tissues (Y-axis), that is, cerebrum (top), liver (middle), and kidney (bottom), of fetuses of heterozygous mothers administered copper. $\mathbf{~}$, hemizygous fetuses; $\boldsymbol{\bullet}$, heterozygous; $\boldsymbol{\Delta}$, normal. The placental copper concentration is inversely proportional to the cerebral concentration $(r=0.7982)$ and directly proportional to the renal concentration $(r=0.9222)$. 
with $\mathrm{Cu}$ allowed discrimination of the fetal genotype (Fig. 2). The copper concentration of br/y fetuses was significantly higher than that of br/ + or normal fetuses. The placental copper concentration in $5 \mathrm{br} / \mathrm{y}$ fetuses was $5.8 \pm 0.9$ (mean $\pm \mathrm{SD}$ ) $\mu \mathrm{g} / \mathrm{g}$ wet weight. The value for $1 \mathrm{br} /+$ fetus was 3.0 and that for 6 normal fetuses $2.6 \pm 0.5$ (mean $\pm \mathrm{SD}$ ) $\mu \mathrm{g} / \mathrm{g}$ wet weight. The wet weight and zinc concentration of placenta showed no significant differences. The means \pm SD of the placental wet weight and zinc concentration in all 12 fetuses were $99.9 \pm 18.3 \mathrm{mg}$ and $18.0 \pm 1.0 \mu \mathrm{g} / \mathrm{g}$ wet weight, respectively. Since the placenta of $\mathrm{br} / \mathrm{y}$ fetuses contained a higher copper concentration than br/ + or normal fetuses, the placental copper concentration could be used to distinguish br/y fetuses from $\mathrm{br} /+$ fetuses and normal fetuses.

\section{DISCUSSION}

Copper retention in the brain, liver, and kidney of br/y and br $/+$ suckling mice was the same, lower, and higher than in normal mice, respectively (6). If the retention in each tissue of fetuses aged 18 days gestation was considered to be similar to that of suckling mice, these differences in retention in tissues might explain the different responses of copper concentrations in tissues of $\mathrm{br} / \mathrm{y}$ and $\mathrm{br} /+\mathrm{fetuses}$ to the copper administration. The copper concentrations in cerebrum and liver of hemizygous males increase a little on 1 day of age and then decrease to 11 days of age (9). The increased copper concentration in cerebrum of normal mice with the administration in utero was considered to be maintained at a higher level than that without the administration after birth(12). Therefore, the increased copper concentration in cerebrum of hemizygous males at 18 days gestation is expected to be maintained after birth.

The copper concentrations in cerebrum and liver of heterozygous females, which were lower than in normal mice at 18 days gestation (Table 3) and at 21 days gestation $(9)$, increased after birth to reach normal levels $(9,13)$. The lower uptake $(13)$ or retention $(6,15)$ was proposed to be the cause of the abnormal hepatic copper metabolism in heterozygous females. The renal copper concentration in heterozygous females was higher than in normal mice after birth $(9,13)$, which was caused by the higher retention $(15,16)$. The results presented in this paper corresponded to these previous reports. Additionally, copper administration reduced the difficulty experienced by the heterozygous mothers in maintaining their pregnancies (Table 1). The lack of a change in the hepatic copper concentration of the heterozygous mothers suggested the intestinal malabsorption and the impaired hepatic uptake of copper (Table 2). The administered copper did not accumulate in the kidneys of the heterozygous mothers (Table 2). Copper administration by our method is safe for heterozygous mothers, as judged from the renal copper accumulation, which may be related with brain damage (Tanaka, H. and Kasama, T., et al., Brain Dev., in press). Our results showed that the administration led to several improvements in the heterozygous mothers, but no exacerbation of the 
impaired homeostasis, even if the other minor changes observed were taken into consideration.

The responses of normal fetuses, at 18 days gestation, of normal mothers to the copper administration (Table 3) corresponded to those of neonates within $24 \mathrm{~h}$ after birth, previously reported by us (12). The administration increased the cerebral copper concentration without disturbing fetal growth. If the administration was continued to delivery, the neonate was expected to show the same responses as the fetus at 18 days gestation. Although a smaller amount of copper was transferred to fetuses from the heterozygous mothers than from the normal mothers (14), the cerebral copper concentration in normal fetuses of both heterozygous and normal mothers increased (Table 3 ). The several changes in the copper or zinc concentration in tissues of normal fetuses observed were not considered to be harmful as to fetal growth after birth, because normal mice born to heterozygous or normal mothers with copper administration grew as well as normal ones born to normal mothers without the administration (data not shown). Since the copper concentrations in the cerebrum, liver, and kidneys of normal mice rapidly increased after birth (9), these several increases observed at 18 days gestation are considered to be compensated for by these rapid increases.

The placental copper concentration could be used to distinguish br/y fetuses from $\mathrm{br} /+$ and normal fetuses, and reflected the copper concentrations of the cerebrum and kidney (Fig. 2). The placenta of br/y fetuses contained a higher copper concentration than that of $\mathrm{br} /+$ or normal fetuses. The same trend for the placental copper concentration of fetuses, at 20-21 days gestation, of heterozygous mothers without copper administration was reported(9). The difference in the placental copper concentration with fetal genotype at 18 days gestation is considered to be maintained to 20-21 days gestation, just before birth. These data suggested that the placental copper concentration could be used to decide whether a fetus was br/y or another genotype, regardless of the maternal drinking fluid. The placental copper concentration is considered to be useful for diagnosis, and for the estimation of the cerebral and renal copper concentrations.

The low activities of copper-containing enzymes, such as superoxide dismutase and cytochrome oxidase, are other problems in Menkes' disease and brindled mice, as well as the abnormal copper distribution. Copper supplementation to fetal mice by means of oral copper administration to normal mothers could not improve such enzyme activities (12), since the activities of superoxide dismutase and cytochrome oxidase were reported to rapidly increase after birth $(17,18)$. Copper supplementation after birth did increase enzyme activities in brindled and normal mice $(12,19)$. Copper supplementation to hemizygous males after birth increased the activity of cytochrome oxidase in the cerebrum(19). These data suggest that copper supplementation after birth is also necessary to improve enzyme activities and abnormal copper distribution.

We report here the possibility of fetal therapy by means of oral copper administration to heterozygous mothers. The administration partially improved the 
abnormal copper distributions in the hemizygous and heterozygous fetuses, that is, the increase in the cerebral copper concentration. The administration did not exacerbate renal copper accumulation in the hemizygous and heterozygous fetuses, and heterozygous mothers. These results indicate that copper supplementation to fetuses by means of oral copper administration to heterozygous mothers could become one therapy, even if supplementation to neonates remains necessary. The long-term effects of the administration also require investigation.

This work was supported by Grant No. 62A-5 from the National Center of Neurology and Psychiatry of the Ministry of Health and Welfare of Japan, and by a Grant for Development of New Drugs from the Ministry of Health and Welfare of Japan.

We wish to thank Dr. Masataka Arima, Vice Director of the National Center Hospital for Mental, Nervous and Muscular Diseases, for his useful advice.

\section{REFERENCES}

1) Menkes, J. H., Alter, M., Steigleder, G. K., Weakley, D. R., and Sung, J. H. (1962): A sex-linked recessive disorder with retardation of growth, peculiar hair, and focal cerebral and cerebellar degeneration. Pediatrics, 29, 764-779.

2) Hunt, D. M. (1974): Primary defect in copper transport underlies mottled mutants in the mouse. Nature, 249, 852-854.

3) Danks, D. M. (1983): Hereditary disorders of copper metabolism in Wilson's disease and Menkes' disease, in The Metabolic Basis of Inherited Disease, ed. by Stanbury, J. B., Wyngaarden, J. B., Frederickson, D. S., Goldestein, J. L., and Brown, M. S., McGraw-Hill, Inc., New York, pp. 1251-1268.

4) Sander, C., Niederhoff, H., and Horn, N. (1988): Life-span and Menkes kinky hair syndrome: report of a 13-year course of this disease. Clin. Genet., 33, 228-233.

5) Mann, J. R., Camakaris, J., Danks, D. M., and Walliczek, E. G. (1979): Copper metabolism in mottled mouse mutants: copper therapy of brindled $\left(\mathrm{Mo}^{\mathrm{br}}\right)$ mice. Biochem. J., 180, 605-612.

6) Mann, J. R., Camakaris, J., and Danks, D. M. (1979): Copper metabolism in mottled mouse mutants: distribution of ${ }^{64} \mathrm{Cu}$ in brindled $\left(\mathrm{Mo}^{\mathrm{br}}\right)$ mice. Biochem. J., 180, 613-619.

7) Suzuki, K., and Nagara, H. (1981): Brindled mottled mouse: morphological changes of brain and visceral organs in hemizygous males following copper supplementation. Acta Neuropathol. (Berl), 55, 251-255.

8) Nagara, H., Yajima, K., and Suzuki, K. (1981): The effect of copper supplementation on the brindled mouse. J. Neuropathol. Exp. Neurol., 40, 428-446.

9) Camakaris, J., Mann, J. R., and Danks, D. M. (1979): Copper metabolism in mottled mouse mutants: copper concentrations in tissues during development. Biochem. J., 180, 597-604.

10) Nooijen, J. L., De Groot, C. J., van den Hamer, C. J. A., Monnens, L. A. H., Willemse, J., and Niermeijer, M. F. (1981): Trace element studies in three patients and a fetus with Menkes' disease. Effect of copper therapy. Pediatr. Res., 15, 284-289.

11) Tønnesen, T., Horn, N., Søndergaard, F., Jensen, O. A., Gerdes, A.-M., Girard, S., and Damsgaard, E. (1987): Experience with first trimester prenatal diagnosis of Menkes disease. Prenatal Diag., 7, 497-509.

12) Kasama, T., and Tanaka, H. (1988): Effects of copper administration on fetal and 
neonatal mice. J. Nutr. Sci. Vitaminol., 34, 595-605.

13) Evans, G. W., and Reis, B. L. (1978): Impaired copper homeostasis in neonatal male and adult female brindled $\left(\mathrm{Mo}^{\mathrm{br}}\right)$ mice. $J$. Nutr., 108, 554-560.

14) Mann, J. R., Camakaris, J., and Danks, D. M. (1980): Copper metabolism in mottled mouse mutants: defective placental transfer of ${ }^{64} \mathrm{Cu}$ to foetal brindled $\left(\mathrm{Mo}^{\text {br }}\right)$ mice. Biochem. J., 186, 629-631.

15) Prohaska, J. R. (1983): Comparison of copper metabolism between brindled mice and dietary copper-deficient mice using ${ }^{67} \mathrm{Cu}$. J. Nutr., 113, 1212-1220.

16) Delhez, H., Prins, H. W., Prinsen, L., and van den Hamer, C. J. A. (1983): Autoradiographic demonstration of the copper-accumulating tissues in mice with a defect homologous to Menkes' kinky hair disease. Pathol. Res. Pract., 178, 48-50.

17) Mavelli, I., Rigo, A., Federico, R., Ciriolo, M. R., and Rotilio, G. (1982): Superoxide dismutase, glutathione peroxidase and catalase in developing rat brain. Biochem. J., 204, 535-540.

18) Rezek, D. L., and Moore, C. L. (1986): Depletion of brain mitochondria cytochrome oxidase in the mottled mouse mutant. Exp. Neurol., 91, 640-645.

19) Phillips, M., Camakaris, J., and Danks, D. M. (1986): Comparisons of copper deficiency states in the murine mutants blotchy and brindled: changes in copper-dependent enzyme activity in 13-day-old mice. Biochem. J., 238, 177-183. 